\title{
EMPODERAMENTO DE MULHERES NO SINDICALISMO DE TRABALHADORES E TRABALHADORAS RURAIS DE MARABÁ (PA)
}

\section{LUCIANA MOREIRA DOS REIS}

O objetivo da dissertação foi analisar o processo de empoderamento das mulheres dirigentes do Sindicato dos Trabalhadores e Trabalhadoras Rurais de Marabá. Para essa pesquisa, o empoderamento foi considerado como ampliação do poder, nas dimensões econômica, pessoal, social e política. A pesquisa é um estudo de caso do Sindicato dos Trabalhadores e Trabalhadoras Rurais de Marabá (PA), com abordagem qualitativa. A metodologia abrangeu pesquisa bibliográfica, pesquisa documental e pesquisa de campo. A coleta de dados ocorreu através de: a) pesquisa documental no acervo do sindicato pesquisado e no acervo da Comissão Pastoral da Terra; b) pesquisa de campo, através de entrevista não-diretiva com 18 pessoas, sendo 11 mulheres e 07 homens. Com o desenvolvimento da pesquisa, identificou-se que as mulheres do STTR de Marabá participaram de lutas e embora obtivessem conquistas, foram vítimas de discriminação e violência doméstica no âmbito e decorrer da militância sindical. Isso é reflexo do caráter processual do empoderamento, sendo esse processo complexo e marcado por contradições, avanços e recuos. O combate à violência doméstica foi um dos indicadores de empoderamento mais citados nas entrevistas realizadas, em todas as suas formas: física, psicológica, sexual, patrimonial e moral. O principal desafio das mulheres é continuar lutando, através de uma agenda permanente, para superar a violência doméstica e a discriminação, garantindo que prevaleça um trabalho de parceria e respeito entre as mulheres e homens do sindicato pesquisado.

Palavras-chave: Mulheres. Empoderamento. Relações de gênero. Sindicalismo de trabalhadores rurais.

Número de páginas: 102

\section{Banca Examinadora:}

Dr. Gutemberg Armando Diniz Guerra (UFPA)

Dr. ${ }^{a}$ Denise Machado Cardoso (UFPA)

Dr. William Santos de Assis (UFPA)

\section{Local e Data de Defesa:}

Sala MAFDS, no dia 14 de março de 2018. 


\title{
REPRESENTAÇÕES DO OUTRO E CONFLITOS NO USO DA TERRA: O CASO DO PDS VIROLA JATOBÁ - ANAPU/PA
}

\author{
ARTHUR ERIK MONTEIRO COSTA DE BRITO
}

A presente pesquisa objetiva analisar conflitos acerca de formas de apropriação e uso dos recursos naturais entre famílias camponesas, tendo como estudo empírico o caso do Projeto de Desenvolvimento Sustentável (PDS) Virola Jatobá, situado na região da Transamazônica, munícipio de Anapu, Estado do Pará. A partir de dados empíricos coletados em trabalho de campo, analisados com o aporte de conceitos sócio-espaciais como Paisagem, Cartografia e Território, buscou-se evidenciar as representações camponesas sobre o Outro e as causas do conflito internalizado neste assentamento rural, enfocando tensões expressas nas Áreas de Uso Alternativo, espaços destinados às práticas produtivas das famílias assentadas. Como parte da metodologia para coleta de dados foram feitas observações direta e participante em campo, entrevistas semi-estruturadas e registros fotográficos. Além disso, foram realizadas coleta e análise de dados espaciais para a confecção de mapas pela equipe de pesquisadores do Projeto Automanejo, no qual participávamos. Como resultado preliminar pôde-se registrar que os conflitos entre camponeses são localmente atribuídos a falsos dualismos, tais como pioneiros-novatos, agricultura-pecuária e Associação Virola Jatobá-Associação Liberdade do Povo, sobre os quais são criados significados e valores diversos, fragmentando as relações sociais entre os segmentos camponeses do assentamento. Como resultado final, vemos que os conflitos têm sua gênese em antagonismos entre grupos sociais com distintas relações com a natureza, demonstrando-se que no PDS Virola Jatobá existem diversas territorializações em construção.

Palavras-chave: Campesinato. PDS Virola Jatobá. Uso da terra. Análise espacial

Número de páginas: 167

\section{Banca Examinadora:}

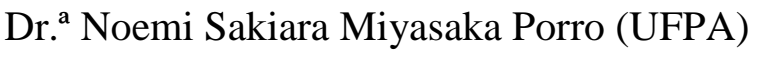

Dr. Fabiano de Oliveira Bringel (UEPA)

Dr. Flávio Bezerra Barros (UFPA)

\section{Local e Data de Defesa:}

Sala MAFDS, no dia 26 de fevereiro de 2018 


\title{
TRANSIÇÃO AGROECOLÓGICA: REFLEXÕES A PARTIR DE AGROECOSSISTEMAS DE CAMPONESES AGROEXTRATIVISTAS NA AMAZÔNIA NUMA PERSPECTIVA POLÍTICA
}

\author{
HUELITON PEREIRA AZEVEDO
}

Esta dissertação trata sobre a transição agroecológica no contexto de agroecossistemas de camponeses agroextrativistas na Amazônia. Esse tema tem gerado controvérsias acadêmicas e desafios políticos importantes para o movimento agroecológico. A presente pesquisa buscou contribuir no aprofundamento deste debate através da análise dos agroecossistemas com base nos aportes da agroecologia política a partir da articulação entre a ecologia política, a teoria dos recursos comuns e o enfoque sistêmico. Os resultados revelam a necessidade da transição agroecológica em função da crise do manejo tradicional dos agroecossistemas dos camponeses agroextrativistas.

Palavras-chave: Agroextrativismo, Recampenização qualitativa, Agroecologia, Amazônia

Número de páginas: 172

\section{Banca Examinadora:}

Dr. William Santos de Assis (UFPA)

Dr. Paulo Petersen (AS-PTA- Agricultura Familiar e Agroecologia)

Dr. Marc Piraux (EMBRAPA)

\section{Local e Data de Defesa:}

Auditório do INEAF, no dia 26 de fevereiro de 2018 


\section{ESTRATÉGIAS DE FAMÍLIAS AGRICULTORAS COM ENFOQUE NO MANEJO DE BACURIZEIROS (PLATONIA INSIGNIS MART.) NO NORDESTE PARAENSE E MARAJÓ}

\section{ERCILENE DE CÁSSIA FERREIRA RODRIGUES}

Esta pesquisa buscou analisar as dinâmicas e as inter-relações existentes entre o manejo de bacurizeiros e as estratégias de famílias agricultoras no Nordeste Paraense e Marajó. A escolha das Mesorregiões do Nordeste Paraense e Marajó como áreas de estudo decorreu da informação corrente de que são áreas produtoras que respondem pela maior oferta de frutos de bacuri no estado do Pará. Para realização do levantamento de campo, optou-se por uma amostragem intencional, considerando-se somente os agricultores familiares que possuíam bacurizeiros nos seus estabelecimentos e que realizavam algum tipo de comercialização dos produtos. Foram aplicados ao total 77 questionários entre os 7 municípios estudados, sendo 57 na Mesorregião Nordeste Paraense e 20 no Marajó. Foi realizado uma Tipologia de sistemas de produção, encontrando-se 4 tipos: bacuri e roça, bacuri e frutíferas, bacuri e pesca e bacuri e previdencia social. Verificou-se que os sistemas de produção com maior grau de diversificação de espécies possuem maior potencial de geração de renda e são os que têm maior renda agrícola e maior renda familiar, esses são os sistemas de produção pertencente ao grupo Bacuri e Frutíferas (T2), que alcançaram valor agregado de $\mathrm{R} \$ 23.140,33 /$ ano. As principais estratégias de reprodução social praticadas pelas famílias entrevistadas foram a diversificação da produção, a produção para o autoconsumo e o emprego em atividades não agrícolas. $\mathrm{O}$ sistema de comercialização de frutos in natura é bastante simples, baseado na coleta de frutos e em distribuídas no curto período de safra. Verificou-se que está ocorrendo uma mudança na comercialização do fruto in natura para a produção de polpa. As principais motivações em realizar o manejo de bacurizeiros apontadas pelas famílias foi a comercialização e beleza da composição do bosque. Este estudo demonstrou que algumas famílias realizam práticas etnotecnológicas para aumentar a produtividade dos frutos, as quais são importantes para resgatar e valorizar o conhecimento tradicional e o valor cultural destas comunidades. Conclui-se ainda que o manejo de bacurizeiros constitui-se uma estratégia familiar importante para a manutenção das famílias no campo e apresenta potencial de crescimento capaz de atender demanda de exportação, importante para geração de emprego e local.

Palavras-chave: Agricultura familiar. Sistemas de produção. Economia rural. Comercialização.

Número de páginas: 115 


\title{
Banca Examinadora:
}

Dr. Osvaldo Ryhoei Kato (EMBRAPA)

Dr. Alfredo Kingo Oyama Homma (EMBRAPA)

Dr. Fabrício Khoury Rebello (UFRA)

Dr. ${ }^{a}$ Maria das Graças Pires Sablayrolles (UFPA)

\section{Local e Data de Defesa:}

Auditório na EMBRAPA, no dia 20 de março de 2018

\section{VÁRZEA OU TERRA FIRME? A (RE) PRODUÇÃO DO SISTEMA FAMÍLIA- ESTABELECIMENTO NA MICROBACIA DO ARICURÁ- CAMETÁ- PARÁ.}

\author{
ANA JULIA MOURÃO SALHEB DO AMARAL
}

Os ambientes de várzeas e de terras firmes são utilizados por populações que habitam as planícies amazônicas, sendo que muitas vezes os moradores podem ou não dispor simultaneamente desses dois ambientes que requerem estratégias diferenciadas de sobrevivência. Dentre as explorações efetuadas, a do açaizeiro, espécie Euterpe oleracea Mart., tem aumentado em virtude da expansão do mercado nacional e internacional. $\mathrm{O}$ rio Aricurá, tributário do Tocantins no seu baixo curso, forma uma microbacia localizada ao sul da cidade de Cametá, Estado do Pará, que é formada por ambientes de várzea e de terra firme, que se apresentam por vezes associados e onde a exploração do açaizeiro constitui uma das principais atividades efetuadas pelos moradores. Assim, as condições dessa microbacia permitem abordarmos, em uma unidade da paisagem, como esses ambientes são utilizados pelas famílias de moradores e quais os fatores de relevância que atuam nas possibilidades de exploração, especialmente as ligadas à produção do açaizeiro, por essas famílias em seus estabelecimentos rurais. Desta forma esta pesquisa teve como objetivo principal avaliar a influência da disponibilidade de áreas de várzeas nas atividades produtivas, em especial na produção do fruto do açaí, e na reprodução socioeconômica do sistema família-estabelecimento. Abordando a pesquisa sob dois ângulos um técnico- produtivo e o outro de natureza socioeconômica, reputando essa junção um elemento diferenciado da referida pesquisa. A pesquisa foi realizada em onze estabelecimentos agrícolas distribuídos entre as comunidades do Aricurá e do Ajó, a pesquisa de campo foi feita em três etapas. Os dados levantados envolveram elementos e categorias de diferentes naturezas: social, econômica, epistêmica e agronômica de acordo com a exigência dos objetivos e da hipótese as seguintes categorias de análise: histórico 
e a dinâmica de vida dos moradores das comunidades; renda familiar; relação de trabalho (relação UT/UC) e mão de obra utilizada; uso e Gerenciamento dos estabelecimentos; sistemas de Produção; análise da paisagem; Diversidade vegetal e índice de desbaste das touceiras. Verificou-se que na microbacia do Aricurá existem três fatores de grande relevância que atuam nas possibilidades de exploração do meio ambiente efetuada pelas famílias em seus estabelecimentos rurais: a disponibilidade de ambiente de várzea, as características da família e o açaí como carro chefe da produção.

Palavras-chave: Ambientes diferenciados. Açaí. Atividades produtivas. Reprodução socioeconômica.

Número de páginas: 146

\section{Banca Examinadora:}

Dr. Paulo Fernando da Silva Martins (UFPA)

Dr. Aquiles Simões (UFPA)

Dr. ${ }^{a}$ Angela May Steward (UFPA)

\section{Local e Data de Defesa:}

Auditório do INEAF, no dia 26 de março de 2018

\section{AS LÓGICAS AGROEXTRATIVISTAS E OS PROJETOS DE DESENVOLVIMENTO AGRÍCOLA NAS ILHAS DO CAPIM, CARIPETUBA E XINGU EM ABAETETUBA-PARÁ}

\section{ALCIENE OLIVEIRA FELIZARDO}

O estudo de intervenções no meio rural amazônico é desafiador, em função tanto das especificidades ligadas ao meio biofísico e humano quanto das lógicas de reprodução presentes nesses territórios. Este trabalho analisa como as lógicas produtivas dos agroextrativistas influenciaram no processo de inovação tecnológica desencadeado por projetos de desenvolvimento agrícola implementados nas Ilhas do Capim, Caripetuba e Xingu em Abaetetuba, Pará. Para atender essa proposta articulam-se os recursos teóricoanalíticos relacionados a três temas centrais, as matrizes produtivas que orientam os projetos de desenvolvimento no meio rural, o processo de introdução de inovações tecnológicas a partir de projetos de desenvolvimento agrícola e o enfoque sistêmico aplicado ao estudo das estratégias produtivas. Optou-se por analisar o "Projeto Produzindo a Inclusão" implementado pela Associação dos Moradores das Ilhas de 
Abaetetuba - AMIA. Verificou-se que as lógicas produtivas das famílias agroextrativistas têm sido determinantes no processo de inovação tecnológica desencadeados por projetos de desenvolvimento agrícola nas Ilhas de Abaetetuba. Isso ocorre em função dos centros de decisão desenvolverem suas estratégias particulares baseadas na endogeneidade das práticas realizadas nos seus estabelecimentos familiares. A identificação da complexidade das lógicas agroextrativistas revela a necessidade de mudança de enfoque nos processos de intervenção pensados para realidades como as Ilhas do Capim, Caripetuba e Xingu, comum no território Amazônico. O enfoque programático, utilizado pelo "Projeto Produzindo a Inclusão" ocasionou a não permanência da inovação tecnológica nos sistemas família-estabelecimento. Diante disso, verifica-se a necessidade de avanços em intervenções que possibilitem o fortalecimento da criação animal com base no enfoque estratégico adotado pelos agroextrativistas.

Palavras-chave: Agroextrativismo, práticas produtivas, Projetos de desenvolvimento e Inovações tecnológica

Número de páginas: 124

\title{
Banca Examinadora:
}

Dr. ${ }^{\text {a }}$ Carla Giovana Souza Rocha (UFPA)

Dr. Aldrin Mario da Silva Benjamin (IFPA)

Dr. William Santos de Assis (UFPA)

\section{Local e Data de Defesa:}

Auditório do INEAF, no dia 09 de abril de 2018

\section{RECUPERAÇÃO FLORESTAL EM AÇAIZAIS DE VÁRZEA SUBMETIDOS AO MANEJO INTENSIVO NO ESTUÁRIO AMAZÔNICO}

\author{
ROSILEIA DA COSTA CARVALHO
}

A recuperação florestal tem sido uma estratégia utilizada pelos ribeirinhos do estuário amazônico para recuperação de florestas fortemente antropizada pela exploração intensiva dos açaizais. Neste trabalho buscamos identificar e analisar o surgimento dessas experiencias de recuperação florestal no município de Abaetetuba. Para estudar a recuperação florestal em áreas de açaizais de várzea foi necessário realizar o zoneamento dessas experiencias, o que resultou em 38 experiencias identificadas e distribuídas na 
região de várzea. Identificando suas características e natureza, realizando assim uma tipologia, que compõe o primeiro artigo deste trabalho. No segundo artigo nos focamos em analisar as trajetórias dessas experiencias, partindo de um estudo detalhado de um estabelecimento por cada tipo encontrado, entendendo os fatores históricos decisivos para a diferenciação das trajetórias, analisamos também as lógicas de mudanças das práticas no manejo dos açaizais, percebendo que por vezes ocorre a confluência de diversas lógicas, acionadas pelos ribeirinhos para tomada de decisões. Para isso foi necessário realizar entrevistas retrospectivas com as famílias escolhidas para o estudo detalhado, totalizando 4 famílias. Também buscamos identificar os fatores que influenciaram a conformação do cenário das experiencias de recuperação florestal, dentre eles principalmente a destinação de créditos para incentivo à recuperação da diversidade florestal. No terceiro e último artigo buscamos compreender como as experiencias de recuperação florestal nas áreas de açaizais tem refletido nos saberes e práticas dos ribeirinhos. Encontramos uma variedade de estratégias utilizadas no manejo dos açaizais que incorporam vários níveis de saberes, variáveis externas como o mercado e assistência técnica influenciam nas mudanças dessas práticas e saberes. Constatamos que nem sempre mudança de saberes representa mudanças práticas, tendo em vista que o ribeirinho pode não dispor de recursos para realiza-las. E que as estratégias produtivas podem ser constituídas de conhecimentos tradicionais, bem como de novos saberes.

Palavras-chave: agricultura familiar; ribeirinhos; floresta de várzea; recuperação florestal.

Número de páginas: 106

\section{Banca Examinadora:}

Dr. ${ }^{a}$ Lívia de Freitas Navegantes Alves (UFPA)

Dr. ${ }^{a}$ Nathalie Elisabeth Cialdella (CIRAD)

Dr. ${ }^{a}$ Angela May Steward (UFPA)

\section{Local e Data de Defesa:}

Auditório do INEAF, no dia 20 de abril de 2018 


\title{
OS LIMITES DA INCLUSÃO SOCIAL: AGRICULTORES INTEGRADOS ÀS AGROINDÚSTRIAS DE DENDÊ NO PARÁ
}

\author{
DÉRICK LIMA GOMES
}

A expansão do cultivo de dendê no estado do Pará é um fenômeno que tem recebido grande destaque, noticiário e acadêmico. Com o apoio de políticas públicas e devido à sua aptidão agroclimática, o Nordeste paraense tornou-se o maior produtor da oleaginosa no Brasil. A justificativa para a instalação de empresas na mesorregião baseou-se na promulgação do desenvolvimento regional, da geração de empregos e da inclusão social dos agricultores familiares locais por meio da integração às agroindústrias que produzem dendê. Objetivamos analisar, nesse contexto, como a -inclusão sociall evidencia-se para os agricultores integrados, tendo como lócus empírico o município de Garrafão do Norte (PA). A metodologia utilizada apoiou-se, sobretudo, em entrevistas com uso de questionários semiestruturados e em entrevistas abertas, baseadas em um roteiro, com agricultores locais. Os dados foram sistematizados no programa Microsoft Office Excel e depois analisados segundo o Teste — $t \|$ de Student pareado. Também realizamos revisão de literatura e de documentos pertinentes sobre a temática. Constatamos, ao final da pesquisa, que os limites da inclusão social, título do presente trabalho, residem tanto na forma marginal com que essa ainda acontece para os agricultores, pois desconsidera suas culturas tradicionais e segue prioritariamente a lógica da cadeia produtiva do dendê; quanto nos efeitos práticos que limitam o acesso a créditos, assistência técnica e cursos ao atendimento das demandas da produção da oleaginosa, sem considerar $o$ estabelecimento todo como um sistema de produção. Diante de processos anteriores e atuais de exclusão, a inclusão marginal atual é percebida pelos agricultores como uma oportunidade que lhes foi historicamente negada, daí visualizarem na integração à agroindústria local não só a oportunidade de adquirirem melhorias, mas de manter o modo de vida de suas famílias enquanto agricultoras.

Palavras-chave: Dendeicultura. Inclusão social. Agricultores familiares. Integração produtiva. Garrafão do Norte

Número de páginas: 136

\section{Banca Examinadora:}

Dr. Heribert Schmitz (UFPA)

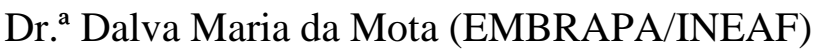

Dr. Benedito Ely Valente da Cruz (UEPA)

DR. ${ }^{a}$ Edna Ramos de Castro (UFPA)

\section{Local e Data de Defesa:}

Auditório do INEAF, no dia 11 de maio de 2018 


\title{
EXPERIÊNCIAS DE RECUPERAÇÃO FLORESTAL PRATICADAS POR AGRICULTORES FAMILIARES DO NORDESTE DO PARÁ
}

\author{
RENAN DO VALE CARNEIRO
}

Os agricultores familiares do Nordeste do Pará, tradicionalmente desenvolvem práticas de recuperação florestal em seus lotes, e mais recentemente vem adaptando-as. Nesta pesquisa buscou-se analisar as experiências que vêm sendo realizadas por estes sujeitos e compreender os principais desafios e processos em curso. Para isto, a pesquisa apoiou-se em princípios da transdisciplinaridade e da abordagem sistêmica, e assim realizou um levantamento de 60 ex-periências em quatro municípios da mesorregião Nordeste do Pará: Capitão Poço, Irituia, Bragança e Tomé-Açu. No primeiro artigo, a partir da realização de uma tipologia da recupe-ração florestal compreendeu-se as peculiaridades destas experiências, destacando as percep-ções e motivações dos agricultores. Assim foram encontrados os cinco principais tipos de recuperação florestal praticados pelos agricultores familiares da região: regeneração natural, quintal agroflorestal e os três tipos de sistemas agroflorestais (pouco diversificado, diversifi-cado e altamente diversificado). O segundo artigo, a partir de pesquisa de campo, analise es-pacial e de dados secundários, verificou a integração das práticas que vem sendo realizadas pelos agricultores e que possibilitaram a ampliação das escalas de recuperação florestal em algumas regiões específicas, e das políticas públicas que tem atuado na região, com maior ou menor eficiência. O terceiro artigo analisa, sob uma perspectiva espaço-temporal, a diversida-de de trajetórias que envolvem os processos de recuperação florestal praticados por agriculto-res familiares. Foi encontrado um padrão nas trajetórias estudadas, onde os sistemas de pro-dução dos agricultores inicialmente passam por um processo de intensificação do uso da terra, em seguida atingem um ápice de crise e, a partir daí, começam um processo de diversificação produtiva, em busca da valorização das terras já abertas. Os resultados ajudaram a concluir que a recuperação florestal praticada pela agricultura familiar no Nordeste do Pará possui tra-ços de práticas tradicionais, mas também inovadores, sinalizando assim um quadro ascendente de mudanças. Existe ainda uma confluência de motivações, que tem incentivados estes agri-cultores a desenvolverem este tipo de pratica, seja através de valores típicos destes sujeitos ou a partir da atuação pública frente aos problemas ambientais. E assim, o cenário local, portan-to, inspirado em paradigmas sociais, ambientais e econômicos, parece apontar novos rumos produtivos para a Amazônia Oriental.

Palavras-chave: Agricultura familiar. Recuperação florestal. Nordeste do Pará. Amazônia oriental

Número de páginas: 129 


\title{
Banca Examinadora:
}

Dr. ${ }^{a}$ Lívia de Freitas Navegantes Alves (UFPA)

Dr. ${ }^{a}$ Emilie Coudel (CIRAD)

Dr. Carlos Valério Aguiar Gomes (INEAF/UFPA)

\section{Local e Data de Defesa:}

Auditório do INEAF, no dia 25 de maio de 2018

\section{O MOVIMENTO DOS TRABALHADORES RURAIS SEM TERRA CONSTRUINDO A LUTA NO COTIDIANO: A EXPERIÊNCIA DO ASSENTAMENTO 26 DE MARÇO, EM MARABÁ (PA)}

\author{
EVANDRO CARLOS COSTA NEVES
}

O objetivo deste trabalho é compreender a atuação cotidiana do Movimento dos Trabalhadores Rurais Sem Terra (MST) no que concerne à sua organização e à criação de seus quadros interpretativos (frames), além do desenvolvimento de seus repertórios de ação coletiva em um assentamento rural no Sudeste do Pará. Para alcançar os objetivos propostos, a pesquisa teve como base teórica a Teoria da Mobilização Política, que constitui as teorias dos movimentos sociais (GOHN, 1997), e mobilizou contribuições específicas de Charles Tilly $(1979 ; 1981)$ sobre os repertórios de ação coletiva e de estudos sobre os quadros interpretativos (SNOW et al., 1986; SNOW; BENFORD, 1988; 2000). Com isso, desloca-se o entendimento dos movimentos sociais enquanto anomalia do corpo social ou como resultado de reivindicações não canalizadas e passa-se a percebêlos como portadores de ideias, construtores de significados, capazes de organizar sua própria compreensão da realidade e, portanto, como detentores de um grande potencial para a mudança da mesma. A área de pesquisa é o Assentamento 26 de Março, antiga fazenda Cabaceiras de propriedade da família Mutran, atualmente sob a organização preponderante do MST. Foram realizadas pesquisas de campo entre os meses de março e julho de 2017 e fevereiro de 2018. Os resultados apontam que a criação do assentamento em 2008 proporcionou uma mudança na estrutura organizativa mediante a necessidade de divisão dos lotes e distribuição das famílias. Ao mesmo tempo, os repertórios de ação coletiva arrefeceram e cederam lugar a formas de ação mais individuais, enquanto que os quadros interpretativos passaram a enfrentar desafios para a sua realização diante da institucionalização do território por meio da política de reforma agrária.

Palavras-chave: MST. Quadros interpretativos, Repertórios de ação coletiva, Assentamento 26 de Março, Reforma Agrária

Número de páginas: 156 


\section{Banca Examinadora:}

Dr. Heribert Schmitz (UFPA)

Dr. Luis Fernando Cardoso e Cardoso (UFPA/IFCH)

Dr. Fabiano Bringel (UEPA)

\section{Local e Data de Defesa:}

Auditório do INEAF, no dia 23 de agosto de 2018 